\title{
FTIR Measurement of Human Energy Fields (Evidence of the Existence of Human Inner Power)
}

\author{
Anak Agung Ngurah Gunawan ${ }^{1,2 *}$, Albert Sulaiman ${ }^{3}$, Anak Agung Ngurah Franky Kusumanegara ${ }^{1}$, Mada Ramadan ${ }^{1}$, \\ Mulana Ramadan ${ }^{1}$ \\ ${ }^{1}$ Faculty of Mathematics and Natural Sciences, Universitas Udayana, Bali 80361, Indonesia \\ ${ }^{2}$ LBD Sinar Putih, Cabang Bali, Denpasar 80111, Indonesia \\ ${ }^{3}$ Research Center for Physics-Indonesian Institute of Science (LIPI), Tanggerang Selatan 15311, Indonesia
}

Corresponding Author Email: a.a.ngurahgunawan@unud.ac.id

https://doi.org/10.18280/i2m.200307

Received: 6 November 2020

Accepted: 31 May 2021

\section{Keywords:}

FTIR, human energy fields, human inner power

\begin{abstract}
It was argued that human energy consists of physical energy that related to metabolism in the human body and the invisible part represented by the human energy field (HEF). This energy can be generated by a person by using a special excercise. In term of Indian metaphysical theories this energy is called "Chakras" which represents an integrated energy centers. The paper investigates the measurement the Chakra energy by looking at the effect of this energy on the molecular structure of mineral water. The experiment is carried out by providing Chakra energy generated by varying Jurus to a water sample and measured in FTIR. The existence of Chakra energy then analyzed by its effect on the spectrum. The results show that Fourier transform infrared spectroscopy (FTIR) spectra of the mineral water has given Chakra energy have transmitance lower than normal mineral water. The Chakra energy reduce the transmittance but the majority of them does not change a pattern or shift the top of the spectrum. The explicit energy of molecular vibration will be studied by using the Fourier decomposition. This shows that a weakening of molecular vibration occurs to the higher Jurus with a decline in the amplitude of vibration almost half or less.
\end{abstract}

\section{INTRODUCTION}

It was argued that the human has for both visible and invisible part which are called material system and the energytic system respectively [1]. Visible of human energy usually is related to metabolism in the human body. The measurement of human metabolism has been done for a very long time since 1614 by using control of weighing himself before and after several daily activities. In daily life, visible human energy is measured in terms of energy expenditure i.e energy that used for any activities with the unit in calories. The energy was produced by skeletal muscles as a results of any bodily movement. But the problem remains in the exact account of energy balance due to human activities [2-4]. Now believe that human energy not only comes from the admitted that may be measured in calorimeter but can come from invisible parts of the human. A group of researchers joined in the global consciousness project (GCP) try to know the energy from human consciousness. The measurement of energy has been actively carried out at the Princeton Engineering Anomalies Research (PEAR) laboratory where the experiment aims to look at anomalous information transfer and anomalous interactions of mind and machine, using physical systems such as electronic random event generators (REGs).

In some cases, the measurement of energy sources of invisible expressed in the framework of the human energy field or biofield where in term of eastern medicine is called an aura [5]. This field represents human health where for a healthy human, the field is uniform, without brakes, holes, strong outbursts, of the optimal size. The energy fields can be measured by gas discharge visualization (GDV) technique [6, 7]. This energy can be generated by a person by using a special exercise. In term of Indian metaphysical theories this energy is called "Chakras" which represents an integrated energy centers. Several instrument have been developed to measure this energy such as the Inneractie Aura Video system [8]. The measurement of energy chakra has done some researchers, for example, this energy measured by an electric current flowing in the human body by attaching electrodes in areas where energy chakra considered centralized [9]. The energy was interpreted from the fluctuation of current in the men without arousing energized with the men when he excites Chakra energy.

In this paper, we measure the effect of an exertion energy (Chakra). The generation of energy similar to Yoga was created by the synchronize of the respiratory and mind. In principle, activating the chakras in our bodies is almost the same as yoga, namely by moving our bodies according to the rhythm of our breath, by taking a slow breath accompanied by very relaxed body movements, then holding the breath in the diaphragm for a few minutes, then exhaling slowly according to the rhythm of our body movements. This was done repeatedly. The yoga energy measured by instrument electroencephalography (EEG) where the device records the electrical activity generated by voltage fluctuations from the ionic flow provides a quantitative and non-invasive approach to the response of a brain due to respiratory activity [10]. The largest single component of the human body is water with an 
average of roughly $60 \%$ [11]. Human health and metabolism are determined by the water content in the human body so that the energy measurement of the human chakra can be represented by looking at its effect on water. The different spectral patterns with different internal energy strengths and different peak waves with different internal strengths can be obtained by the FITR spectrometer. We measure chakra energy flow at a pot containing mineral water by looking at the molecular structure of water through Fourier transform infrared spectroscopy (FTIR).

\section{METHODS}

The research is conducted by ways of measuring the effects of the energy generated by some person against an object in this case, is water. To produce energy these people have been through special exercises with different kinds of training called the Jurus. Every Jurus was aimed at produces certain specific energy. Exercise is done as follows, 1) Do the meditation by sitting, cris-cross applesauce breathe, feel the power that goes and flows in blood circulation. Hold the breath for a minute in the stomach and waste slowly through the mouth. Do during 10 times to our minds quiet. 2) do the basic Jurus until 100 times and some another Jurus until 12 times. And came the desired so made the power to a water sample in a container. Energy from Cakra was not measured directly but by considering its impacts on a water sample that measured using Fourier-Transform Infrared Spectroscopy (FTIR). The step by step of experiments were conducted as follow: First, weighing a solvent $(\mathrm{KBr})$ with 0.00448 grams. Enter a solvent $(\mathrm{KBr})$ into the available box, and enter into the FTIR to measure spectra background of the solvent. Enter a solvent $(\mathrm{KBr})$ into the available box, and enter into the FTIR to measure spectra background of the solvent. Input a solvent $(\mathrm{KBr})$ and water into the box and then use FTIR to get the spectrum. This is the sample spectrum. Created a substance a solvent and water to the box and then perform the transfer of Chakra energy, through breathing slowly and apply the Jurus through the hand into the sample and bring forth the breath through the nose slow down. After 1 minute, measure the solvent with FTIR. Use the similar way with another Jurus.

\section{RESULTS AND DISCUSSION}

As mention above, the effects of Chakra power is not measured directly with an instrument but by looking at the influence of power in the form of the water spectrum. In principle, the Cakra can be obtained with similar way with Yoga. This is a mind body intervention which helps to attain a calm and stable mental state. The brain and body should be rest by using voluntary breath regulation. The FTIR of water sample and water sample with Chakra is depicted in Figure 1. In this paper, we use mineral water as a sample. The water is the most important matter in human daily life. In the molecular of view, the water is formed by a dense network of a hydrogen bond with a specific orientation or structure. By using FTIR spectroscopy, in principle, we can measure abundances of hydrogen which an important parameter related to the detection of the existence of Chakra energy. In the first experiment (Figure 1) the water sample show the peak of the spectrum at wavelengths $3500 \mathrm{~cm}^{-1}, 2900-2700 \mathrm{~cm}^{-1}, 1700$ $1500 \mathrm{~cm}^{-1}, 1400 \mathrm{~cm}^{-1}, 1200 \mathrm{~cm}^{-1}$ and $800 \mathrm{~cm}^{-1}$. The energy (spectrum) has a similar pattern with the difference only in the amplitude of the transmission. The difference in Jurus will reduce the energy or transmittance of the water molecules.

The Chakra energy given in water samples with varying Jurus has the effect of lower transmittance of FTIR spectra. Jurus Halus 2, Jurus Halus 3, Jurus Bayu and Jurus A1 Manazil show a significant effect on transmittance. In the measurement of FTIR, transmittance represents a molecular vibration. A decrease in transmittance means the molecule is weakening and lowered concentration. It is well known that the IR spectrum of liquid water is composed of two bands frequency i.e. centered around $1650 \mathrm{~cm}^{-1}$ having a Gaussian-like form (bending motion) and ranging from 3000 to $3800 \mathrm{~cm}^{-1}$ in the wider form (strecthing vibration) [12]. The sample shows 5 peak of spectrum with the Gaussian form of the wavelength below $3000 \mathrm{~cm}-1$.

In more depth analysis, we see the detail at wavelengths between 3000 to $2800 \mathrm{~cm}^{-1}$ and as well as a wavelength between 1800 to $1100 \mathrm{~cm}^{-1}$. This is depicted in Figure 2 . Spectra with a wavelength between 3000 until $2800 \mathrm{~cm}^{-1}$ have two peaks with a wavelength 2920 and $2850 \mathrm{~cm}^{-1}$. The peak of spectrum represents an energy at the wavenumber $(\mathrm{k}=1 / \lambda)$ where $\lambda$ is the wavelength.

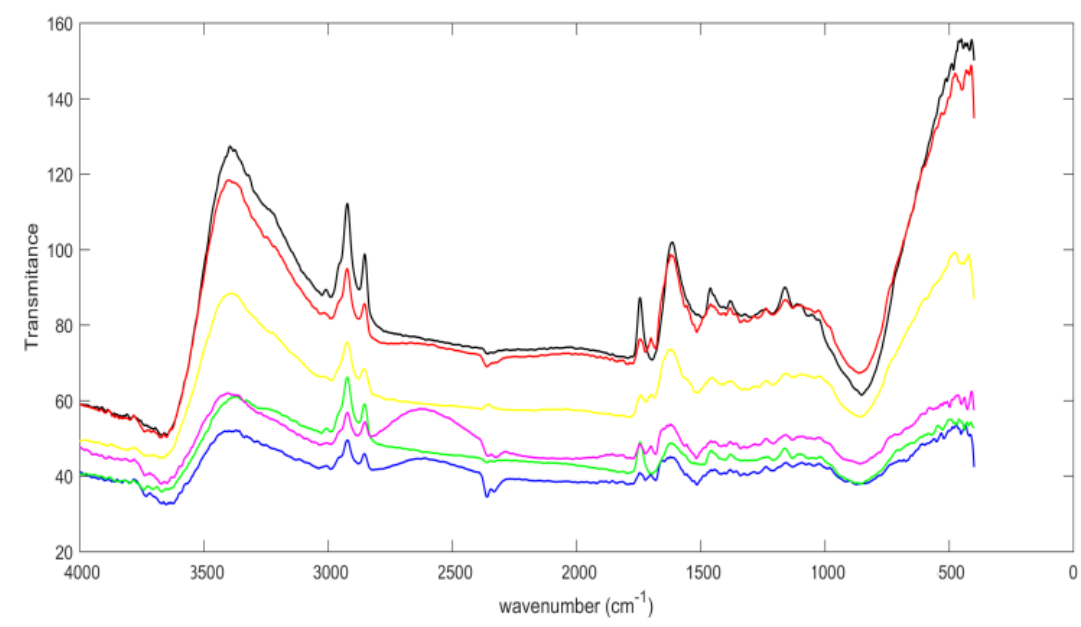

Figure 1. FTIR measurement of water sample and FTIR measurement of water sample after given by the inner power of Cakra with varying exercise (Jurus) 
The Chakra energy would reduce the transmittance but the majority of them does not change a pattern or shift the top of the spectrum. The most extreme shape occurs at the Jurus Halus 2 (the blue line) where it has the intensity of transmittance most low with the value about more than half of the transmittance of the sample. So extreme conditions occurred for a wavelength between 1800 and $1100 \mathrm{~cm}^{-1}$ at a Jurus Halus 2 (the blue line) and Jurus Bayu Pamungkas (the magenta line) almost eliminate the spectrum. This shows that the water molecular bending motion will be damped by Chakra energy. Further, the explicit energy of molecular vibration will be studied by using the Fourier decomposition. Fourier decomposition is arranging a signal based on the frequency of its constituent [13]. Generally speaking, we write a signal in term of a Fourier series. The Fourier decomposition for the signal with the wavenumber 3400, 2900, 2850, 1750 and 1600 $\mathrm{cm}^{-1}$ is depicted in Figure 3. A weakening of molecular vibration occurs to the Jurus Halus 2 and Bayu Pamungkas with a decline in the amplitude of vibration almost half.

The second experiment in a similar way but with more varying Jurus produces the FTIR spectra that can be seen in Figure 4. The figure shows that the FTIR spectra of water samples have are three peaks are between to hang up the wavelengths 3500 until $3000 \mathrm{~m}^{-1}, 2800-2600 \mathrm{~cm}^{-1}$ and 1800 until $1100 \mathrm{~cm}^{-1}$. The chakra energy variations, in general, would reduce the transmittance of a sample of water. The FTIR spectrum expresses the absorption of Chakra energy by water molecules. Transmitancy is the opposite of absorption. The energy absorbed by the water molecules causes the vibrational excitation of the molecules to a higher energy level. Chakra energy reduces transmittance in other words, the water molecule will absorb more energy so that the electrons in the water molecule will be excited or more energetic. The effect of chakra energy will only provide a change in the amount of energy and does not change the wavelength, which means that it does not change the arrangement of the water molecules so that the chakra energy can be applicable for all types of water. Ranging from Jurus Dasar Kasaran (the magenta dot-line) until Jurus Payung 2 (the red line) affected the spectrum is very significantThe spectrum between the wavelengths 3000 until $2800 \mathrm{~cm}-1$ indicated the spectrum which is a flat (no molecular vibration) after worn Jurus Kasaran Dasar, Jurus Halus 2, Jurus Persiapan Syahbandar, Jurus Bayu Pamungkas, Jurus Pantek, Jurus Payung 1and Jurus Payung 2. This is depicted in Figure 5. While in the case of a wavelength between 1800 until $1100 \mathrm{~cm}^{-1}$, just give the significant spectrum at the wavelength of $1600 \mathrm{~cm}^{-1}$. The spectrum with a wavelength of $1600 \mathrm{~cm}^{-1}$ represents the $\mathrm{H}-\mathrm{O}$ $\mathrm{H}$ bending mode (bonds that move up and down). Figure 5 shows that not all Jurus can increase the bond energy of this type. Especially for the Jurus Payung 1 and Jurus Payung 2, it could be said that there is no emerging of the peak of the spectrum. The Amplitude of vibration the Fourier Decomposition is depicted in Figure 6. The higher the level of the then it would weaken vibrations molecules were at the Jurus Payung 2 and Jurus Payung 1 have a very low amplitude.

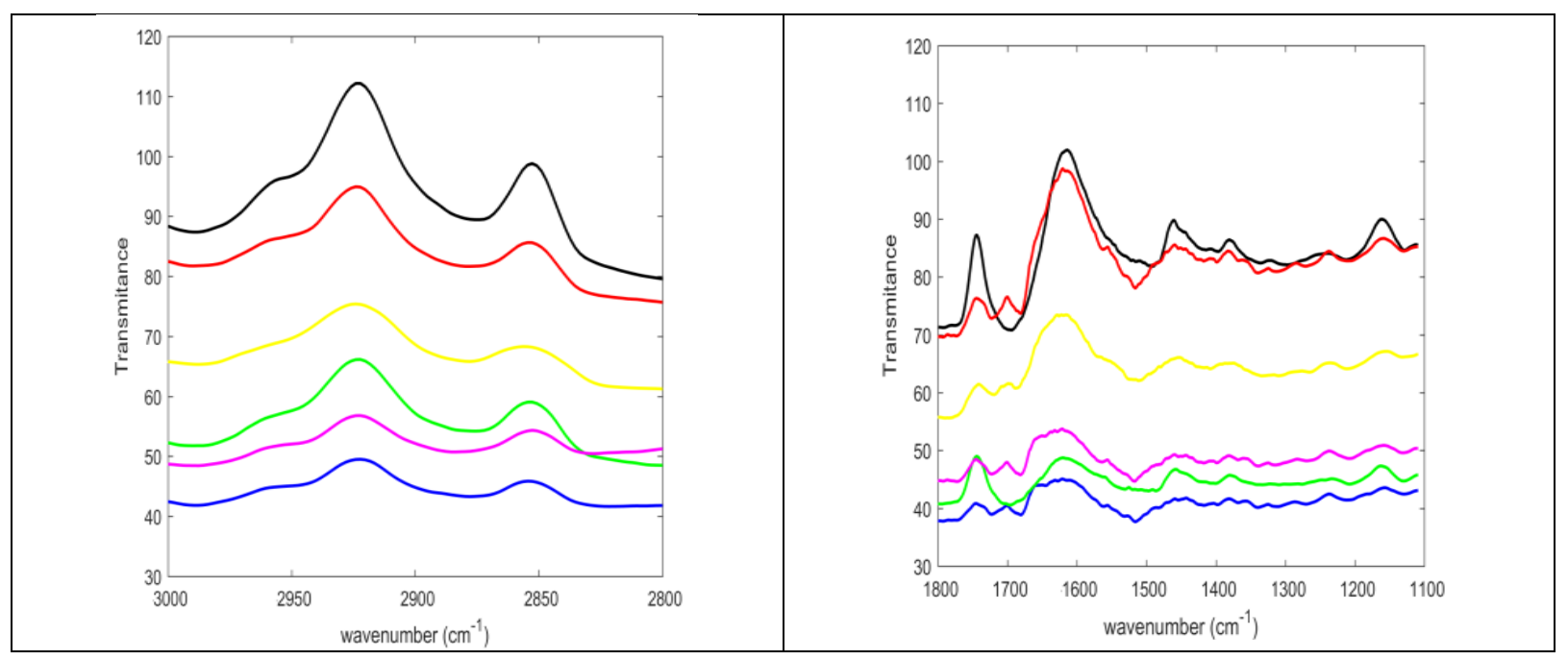

Figure 2. FTIR measurement of water sample for the two band frequency of liquid water

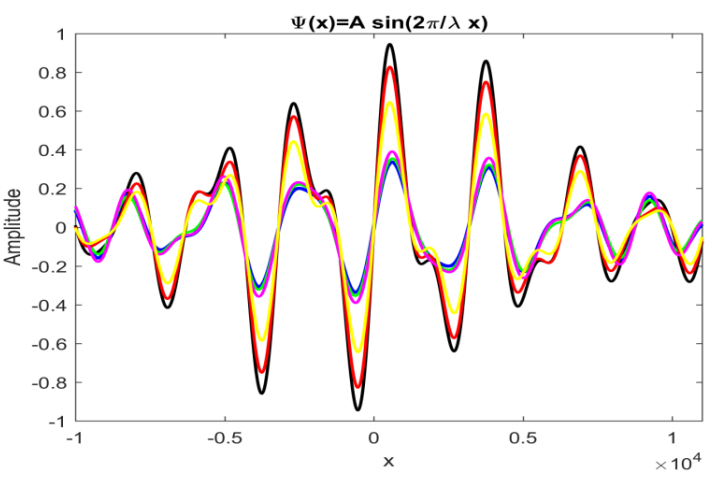

Figure 3. Fourier decomposition of for the two band frequency of liquid water

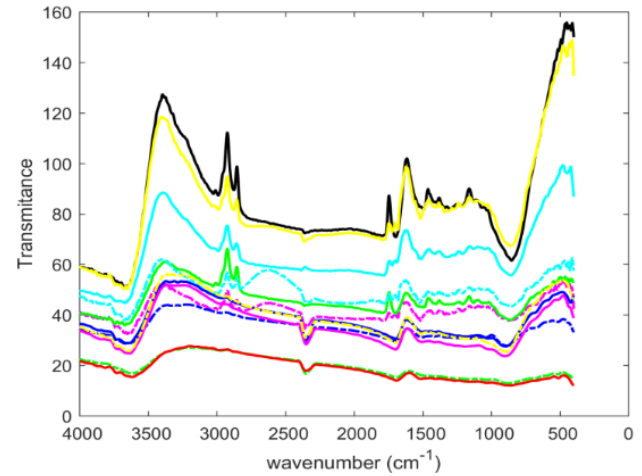

Figure 4. FTIR measurement of water sample in the secod experiment 


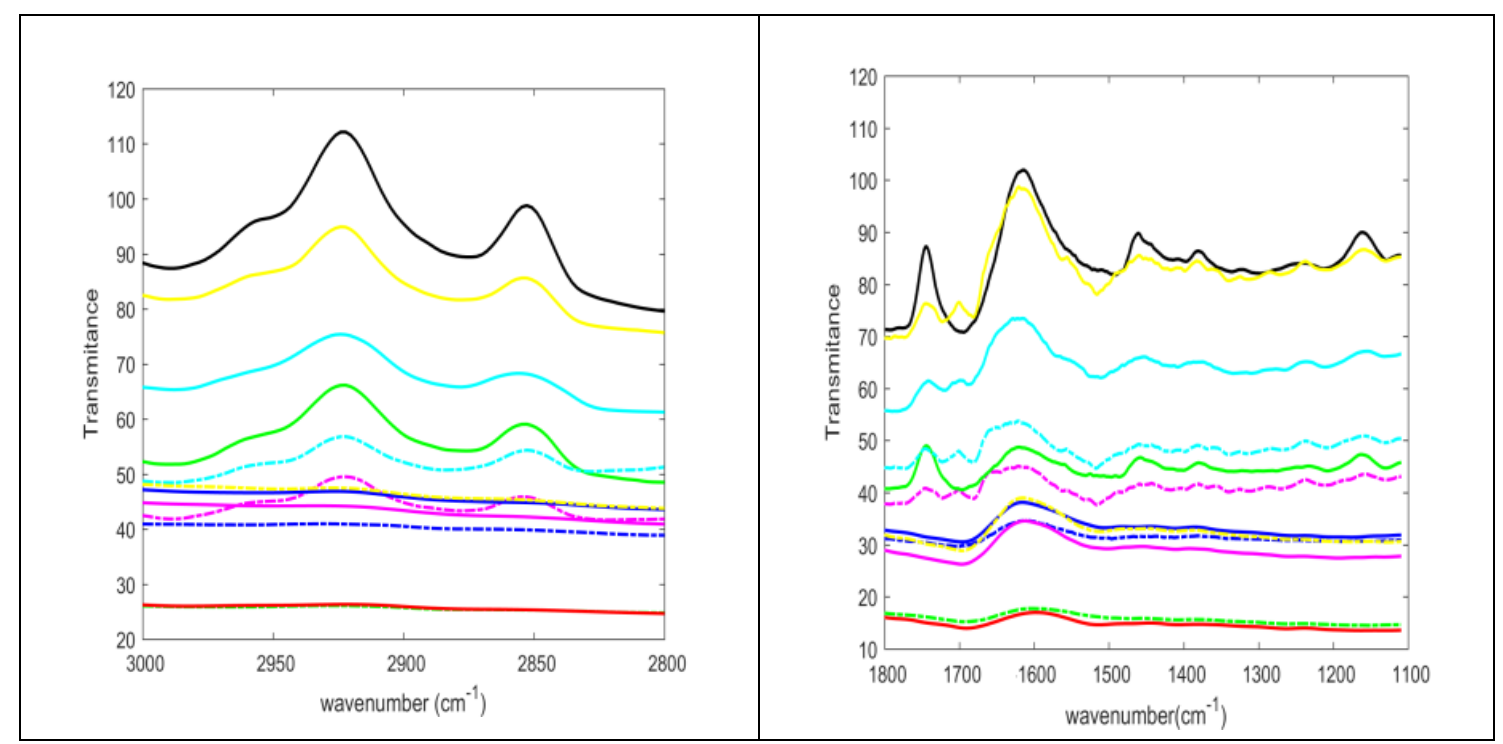

Figure 5. Transmitance in the specific wavelength

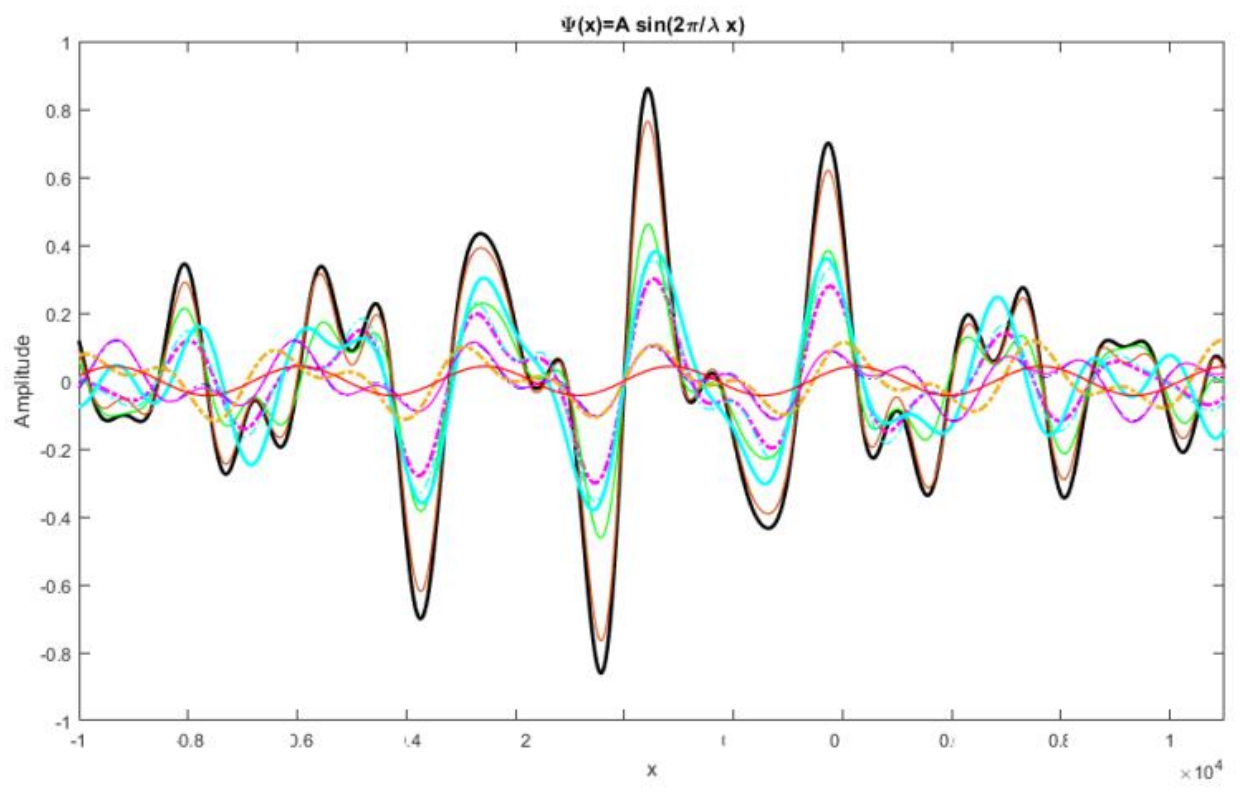

Figure 6. The Fourier decomposition of the measurement for the two band frequency of liquid water of the second experiment

\section{CONCLUSION}

The measurement the Chakra energy by looking at the effect of this energy on the molecular structure of mineral water has been investigated. Varying Chakra energy called the Jurus flow at a pot containing mineral water and measured their effects by looking at the molecular structure of water through FTIR. The importance parameter related to the Chakra detection is called hydrogen bending and molecular vibration which can be measured by using FTIR spectroscopy. In the experiment show the peak of the spectrum (energy) at wavenumber $3500 \mathrm{~cm}^{-1}, 2900-2700 \mathrm{~cm}^{-1}, 1700-1500 \mathrm{~cm}^{-1}$, $1400 \mathrm{~cm}^{-1}, 1200 \mathrm{~cm}^{-1}$ and $800 \mathrm{~cm}^{-1}$ where have a Gaussian-like form. The Chakra energy reduce the transmittance but the majority of them does not change a pattern or shift the top of the spectrum. The explicit energy of molecular vibration will be studied by using the Fourier decomposition. This shows that a weakening of molecular vibration occurs to the higher Jurus with a decline in the amplitude of vibration almost half.

\section{ACKNOWLEDGMENT}

This research occurred because of the collaboration with LBD Sinar Putih. We would like to thank Drs.H.Mudhoffar Assidieq builder of LBD Sinar Putih, Drs. Suharto the Head of Foundation that organizes LBD Sinar Putih, H. Achmadi SH Chairman of LBD Sinar Putih, Syami'ar Jumasa head of LBD Sinar Putih, Ir. H. M.Ali Purnama as the Opening Team of LBD Sinar Putih Bali, We also to thank the anonymous reviewer who has made a lot of improvements to this manuscript.

\section{REFERENCES}

[1] Liu, T. (2018). The scientific hypothesis of an "energysystem" in the human body. Journal of Traditional Chinese Medical Sciences, 5(1): 29-34. https://doi.org/10.1016/j.jtcms.2018.02.003 
[2] Murgatroyd, P.R., Shetty, P.S., Prentice, A.M. (1993). Techniques for the measurement of human energy expenditure: A practical guide. Int J Obes Relat Metab Disord., 17(10): 549-68.

[3] Webb, P. (1991). The measurement of energy expenditure. The Journal of Nutrition, 121(11): 18971901. https://doi.org/10.1093/jn/121.11.1897

[4] Didace, N., Kim, E.K. (2017). Measurement methods for physical activity and energy expenditure: A review. $\begin{array}{llll}\text { ClinNutr } & \text { Res., } & \text { 6(2): }\end{array}$ https://doi.org/10.7762/cnr.2017.6.2.68

[5] Shreya, P., Chowdhury, A.R., Gupta, A. (2015). Monitoring the human health by measuring the biofield "Aura": An overview. International Journal of Applied Engineering Research, 10(35).

[6] Nataliya, K., Phyadragren, C., Meghanathan, N., Isokpehi, R.D., Cohly, H.H.P. (2011). Gas discharge visualization: an imaging and modelingtool for medical biometrics. International Journal of Biomedical Imaging, 2011: 196460. https://doi.org/10.1155/2011/196460

[7] Konstantin, G.K., Peter, M., Dmitry, V.O., Bernard, O.W. (2010). Application of electrophoton capture (EPC) analysis based on gas discharge visualization (GDV) technique in medicine: A systematic review. The Journal of Alternative and Complementary Medicine, 16(1): 1325. https://doi.org/10.1089/acm.2008.0285
[8] Russ, C., Doug, Z., Michelle, M., Sequoyah, C.R. (1990). Examining the Validity of a computerized Cakra Measuring Instrument: A pilot study. Subtle Energies \& Energy Medicine, 15(3): 209-223.

[9] Sulochana, W., Ankita, S., Devendra, K.C. (2016). Measurement of chakra energy: effect of different activities on consciousness. International Journal of Electrical Communication Engineering, 2(1): 1-5. https://doi.org/10.37628/ijece.v1i1.244

[10] Sushma, P., Niranjan, K., Shirley, T., Acharya, B. (2018). Neurophysiological changes determined by the EEG with yoga breathing practices: A mini review. EC Neurology, 10(9): 845-847.

[11] Zhou, S.G., Chen, W. (2018). Human body water composition measurement:methods and clinical application. Zhongguo Yi Xue Ke Xue Yuan Xue Bao, 40(5): 603-609. https://doi.org/10.3881/j.issn.1000503X.10661

[12] Ninno, A.D., Castellano, A.C., Giudice, E.D. (2013). The supramolecular structure of liquid water and quantum coherent processes in biology. Journal of Physics: Conference Series, 442: 012031. https://doi.org/10.1088/1742-6596/442/1/012031

[13] Bloomfield, P. (2000). Fourier Analysis of Time Series (An Introduction). John Wiley and Son, New York. 